\title{
Papers
}

\section{Neonatal examination and screening trial (NEST): a randomised, controlled, switchback trial of alternative policies for low risk infants}

\author{
Cathryn M A Glazener, Craig R Ramsay, Marion K Campbell, Philip Booth, Paul Duffty, \\ David J Lloyd, Alison McDonald, J Anne Reid
}

\begin{abstract}
Objective To evaluate the effectiveness of one rather than two hospital neonatal examinations in detection of abnormalities.

Design Randomised controlled switchback trial. Setting Postnatal wards in a teaching hospital in north east Scotland.

Participants All infants delivered at the hospital between March 1993 and February 1995.

Intervention A policy of one neonatal screening examination compared with a policy of two.

Main outcome measures Congenital conditions diagnosed in hospital; results of community health assessments at 8 weeks and 8 months; outpatient referrals; inpatient admissions; use of general practioner services; focused analysis of outcomes for suspected hip and heart abnormalities.

Results 4835 babies were allocated to receive one screening examination (one screen policy) and 4877 to receive two (two screen policy). More congenital conditions were suspected at discharge among babies examined twice (9.9 $v 8.3$ diagnoses per 100 babies; $95 \%$ confidence interval for difference 0.3 to 2.7 ). There was no overall significant difference between the groups in use of community, outpatient, or inpatient resources or in health care received. Although more babies who were examined twice attended orthopaedic outpatient clinics (340 (7\%) v $289(6 \%))$, particularly for suspected congenital dislocation of the hip (176 (3.6/100 babies) $v 137$ (2.8/100 babies); difference -0.8 ; -1.5 to 0.1$)$, there was no significant difference in the number of babies who required active management $(12(0.2 \%) v 15$ $(0.3 \%))$.
\end{abstract}

Conclusions Despite more suspected abnormalities, there was no evidence of net health gain from a policy of two hospital neonatal examinations. Adoption of a single examination policy would save resources both during the postnatal hospital stay and through fewer outpatient consultations.

\section{Introduction}

Although there is wide acceptance that all newborn babies should be screened for abnormalities, ${ }^{1}$ there is no consensus on how this should be done. Biochemical screening for phenylketonuria and congenital hypothyroidism is effective, but clinical examination for defects in hips, vision, and hearing and other congenital abnormalities is less well founded on scientific evidence. ${ }^{2}$ Up to $12 \%$ of babies may have some detectable abnormality ${ }^{3}$ but not all will impact on health or require action. ${ }^{4}$

For babies born in hospital, clinical neonatal screening is usually carried out twice before discharge, once within 24 hours of birth and again a few days later. The rationale for the first examination is to detect abnormalities that may require early action. The second aims to detect those which may have been missed at the first screening and to detect others which may have become apparent later-such as cardiac defects as the fetal circulation adapts to extrauterine life. $^{5}$

The need for a second examination, however, has been questioned. ${ }^{467}$ We therefore compared the policies for performing one rather than two hospital neonatal screening examinations as judged by their effectiveness in detecting congenital abnormalities and the consequent use of hospital and community resources.

\section{Participants and methods}

The trial was approved by the Grampian Health Board and University of Aberdeen joint ethics committee. All babies delivered at Aberdeen Maternity Hospital between March 1993 and February 1995 were eligible except those discharged home directly from the labour ward (domino births) and those transferred to the neonatal unit within 6 hours of birth. Eligible babies were randomised to one of two policies: one screen policyone neonatal screening examination on day 3 or on the day before expected discharge if earlier; or two screen policy-one screening examination within 36 hours of birth and a second on the day of discharge or on the day before expected discharge if after day 3 . The two screen policy was current practice in the hospital before the trial. Babies allocated to the one screen policy were examined at the latest on day 3 even if they stayed in for longer; babies allocated to the two screen

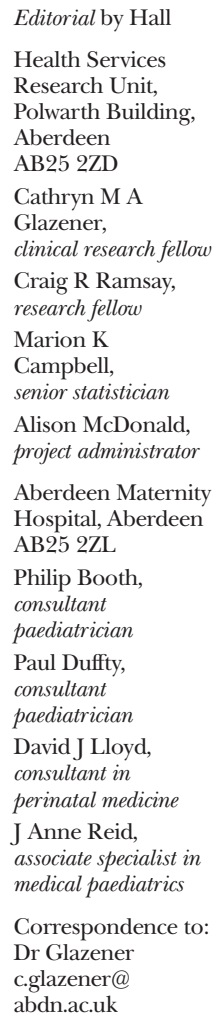

Editorial by Hall Health Services Research Unit, Polwarth Building, Aberdeen AB25 2ZD

Cathryn M A Glazener, clinical research fellow Craig R Ramsay, research fellow

Marion K Campbell, senior statistician Alison McDonald, project administrator

Aberdeen Maternity Hospital, Aberdeen AB25 2ZL

Philip Booth, consultant paediatrician Paul Duffty, consultant paediatrician David J Lloyd, consultant in perinatal medicine J Anne Reid, associate specialist in medical paediatrics

Correspondence to: Dr Glazener c.glazener@ abdn.ac.uk

BMJ 1999;318:627-32 
policy and who stayed in hospital for more than 3 days had their second examination on a later day.

The trial adopted a controlled switchback design, ${ }^{8}$ which is in essence an extended crossover design. This allows the comparison of the screening policies to be unaffected by external changes over time. Babies were allocated to one or other policy depending on their postnatal ward and the calendar month. Each month half the wards in the hospital operated the one screen policy and the rest the two screen policy. Recruitment continued for 2 years. The initial month was allocated at random with crossover to the opposite policy on the first day of each subsequent month. The screening policy to which a ward was assigned could not therefore be influenced by patients or staff. Also, neither the mother nor doctor could choose which ward a baby would be in. Babies were examined by NHS staff, including an associate specialist (JAR), community medical officers, and paediatric senior house officers. Training in and execution of routine neonatal examinations remained unaltered throughout the trial period.

Babies were followed up for their first year of life. The main outcome measures were congenital conditions coded at discharge from hospital; results of the community health assessments at 8 weeks and 8 months; use of general practioner services in the first year of life (for a randomly selected 10\% subsample only); outpatient referrals; and inpatient admissions that involved congenital conditions.

\section{Hospital examinations}

Conditions diagnosed in hospital were identified from the routinely collected and computerised Scottish Morbidity Records (SMR11 and SMR11(E)) by using the ICD-9 (international classification of diseases, ninth revision) codes which referred to congenital conditions likely to be detected by neonatal screening. They were then matched with hand extracted data that described the results of examinations.

\section{Community resources}

The results of the 8 week and 8 month assessments were linked by using the community health index number as a unique identifier. The general practitioners of a $10 \%$ subsample of babies, who were selected at random each month, were sent a questionnaire requesting details of all contacts during the baby's first year of life. General practitioners were blind to the screening policy each baby had received.

\section{Hospital resources}

Babies referred to outpatient departments were tracked by using the computerised Scottish outpatient record (SMR0). Inpatient admissions in the first year of life were found by using the Scottish inpatient and day case record summary sheet (SMR1). This includes details of type of admission, specialty, and conditions diagnosed (with ICD-9 codes). These data collecting systems tracked babies admitted to hospitals throughout Scotland.

The hospital notes of the $10 \%$ of babies, whose general practitioners were sent questionnaires, were examined both to cross validate other methods of data collection and to provide more detailed information

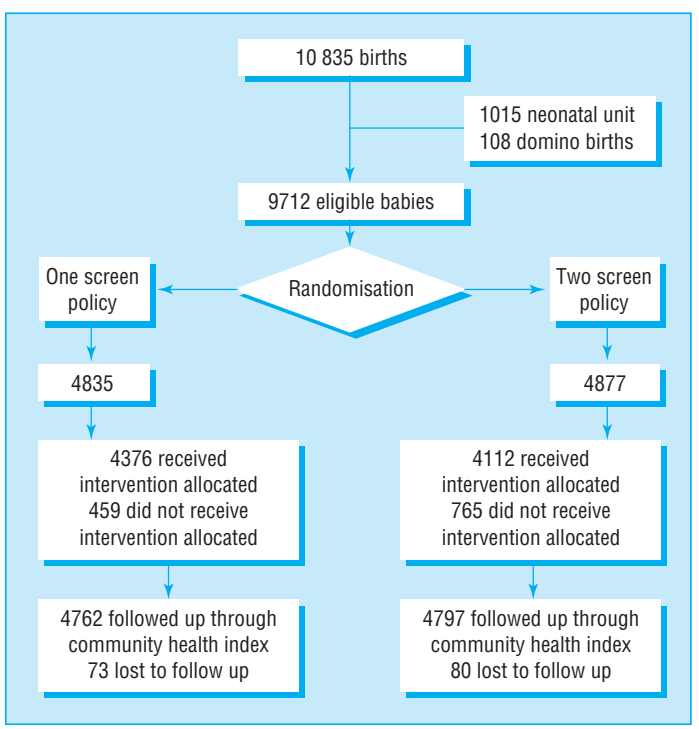

Inclusion of babies in study

about hospital contacts. The data extractor was blinded to the screening policy which each baby had received.

\section{Hip and cardiac anomalies}

All babies suspected of having a hip anomaly were referred to a central orthopaedic clinic. Subsequent management of these babies during their first year of life was described with the clinic's dedicated database and linked to hospital discharge findings with the unique hospital number. Similarly, all babies with cardiac problems were seen centrally (by PB). Data for babies confirmed as having a problem were linked to initial findings by using the hospital number.

\section{Statistical analyses}

As each baby could have more than one condition the results were calculated as the number of diagnoses per hundred babies. Analysis was by intention to treat. Comparisons of rates of abnormality and referral are presented as $95 \%$ confidence intervals for the difference with the normal approximation to the difference between two Poisson variables. ${ }^{9}$ We also calculated $95 \%$ confidence intervals for the difference between two proportions for all main comparisons.

We aimed to recruit between 9000 and 10000 babies, on the basis of an anticipated rate of diagnoses before discharge of $12 \%$. The study had a power of $80 \%$ to detect a relative reduction of $15 \%$ (to $10.2 \%$, with $2 \mathrm{P}<0.05$ ).

\section{Results}

Of the 10835 babies born alive during the 2 year recruitment period, $9712(89.6 \%)$ were eligible for randomisation; 4835 were allocated to the one screen policy and 4877 to the two screen policy (figure). We could not link data on $1.6 \%$ of babies; the numbers lost to follow up because of death $(n=7)$ or moving out of the area were similar in both groups. The groups' baseline characteristics were similar in respect of sex, mode of delivery, birth order, and weight (table 1). Length of stay was the same in both groups (median (interquartile range) 4 (2 to 6 ) days). 
In practice $459(9.5 \%)$ of the one screen policy group were actually examined twice, and 766 (15.7\%) of the two screen policy group were examined once. Reasons for failure to adhere to protocol included detection of serious physical abnormality within the first 24 hours, failure to change from one policy to the other at the start of a month, and babies going home early. Babies allocated to the one screen policy were less likely ever to be examined by a senior member of staff $(56 \%)$ compared with $85 \%$ examined at least once by a senior doctor under the two screen policy (difference $28 \%$; $95 \%$ confidence interval $26 \%$ to $30 \%$ ). Of the two screen policy babies, $32 \%$ were examined on day 4 or later compared with $3 \%$ in the one screen policy group.

Significantly fewer conditions were diagnosed in hospital among one screen policy babies than two screen policy babies (8.3 v 9.9; difference 1.6; 0.3 to 2.7; table 2). This was largely because of fewer suspected musculoskeletal problems, especially suspected hip anomalies (2.8 $v 3.6$; difference 0.8 ; 0.1 to 0.5$)$.

Of the babies for whom we could link data, 37 $(0.38 \%)$ failed to have an assessment at 8 weeks. There was no evidence of an excess of abnormal findings between the groups at either the 8 week or the 8 month community assessment (table 3 ). Nor were there more followed up in primary care or referred to secondary care from this community screening programme, both overall and among the $10 \%$ subsample.

Although the difference in the proportions of babies attending outpatient clinics in their first year of life was not significant $(18.5 \%$ v 19.9\%; difference $-1.4 \% ; 2.9 \%$ to $0.1 \%$; table 4 ), the observed difference was largely explained by more attendances at the orthopaedic outpatient clinic $(6.0 \% v 7.0 \%$; difference $-1 \% ;-1.9 \%$ to $-0.02 \%)$.

In their first year of life $1471(15 \%)$ babies were admitted as inpatients at least once; of these, 369 $(3.8 \%)$ were admitted more than once (table 4$)$. There were no apparent differences between the two groups in the proportion of admissions, the type (whether planned or emergency), or the specialty.

There were no clear differences between the groups in the number with a primary diagnosis of a congenital condition at their first admission ( $1.0 v 0.7$ diagnoses per 100 babies; difference $0.3 ;-0.1$ to 0.7 ) or any admission (1.6 $v 1.4$ diagnoses per 100 babies; difference $0.2 ;-0.3$ to 0.7 ).

The larger number of hip anomalies suspected in hospital under the two screen policy (see table 2) was reflected in more babies being seen at the orthopaedic clinic (125 $v 176$; table 5). There was no difference, however, in the proportion who received active management (outpatient splinting or surgical reduction $0.3 \% v 0.2 \%$; difference $0.1 \% ;-0.1 \%$ to $0.3 \%$; table $5)$. For babies who had been judged normal in hospital (on the basis of a negative Ortolani-Barlow manoeuvre $^{10}$ ) there was no clear difference in the proportion subsequently referred nor in those who then required active management $(0.2 \%$ v $0.1 \%$; difference $0.1 \%$; $-0.1 \%$ to $0.2 \%$; table 5 ). This applied also to those referred because of a family history (table 5). There was no difference in the proportion of babies confirmed to have a cardiac anomaly between the two groups irrespective of whether or not they were diagnosed in hospital (table 5).
Table 1 Baseline characteristics of trial babies* according to whether they underwent one or two neonatal screening examinations before discharge from hospital. Values are numbers (percentages) of babies unless stated otherwise

\begin{tabular}{lcc} 
Characteristic & One screen policy ( $\mathbf{n}=\mathbf{4 8 3 5 )}$ & Two screen policy ( $\mathbf{n = 4 8 7 7 )}$ \\
\hline Boys & $2424(50.1)$ & $2462(50.5)$ \\
\hline Mode of delivery: & & \\
\hline Spontaneous cephalic & $3441(71.2)$ & $3474(71.2)$ \\
\hline Assisted vaginal & $680(14.0)$ & $647(13.3)$ \\
\hline Breech & $43(0.9)$ & $46(0.9)$ \\
\hline Caesarean section & $671(13.9)$ & $710(14.6)$ \\
\hline Mother previously nulliparous & $2092(43.3)$ & $2089(42.8)$ \\
\hline Mean (SD) birth weight $(\mathrm{g})$ & $3460(479)$ & $3457(479)$ \\
\hline
\end{tabular}

*Data source: Scottish morbidity record 11.

Table 2 Congenital diagnoses in neonates at discharge from hospital after birth* according to whether they underwent one or two neonatal screening examinations

\begin{tabular}{lccc} 
Detail & $\begin{array}{c}\text { One screen policy } \\
\text { (No of diagnoses/100 } \\
\text { babies; } \mathbf{n}=\mathbf{4 8 3 5 )}\end{array}$ & $\begin{array}{c}\text { Two screen policy } \\
\text { (No of diagnoses/100 } \\
\text { babies; } \mathbf{n = 4 8 7 7 )}\end{array}$ & $\begin{array}{c}\text { Difference in No of } \\
\text { diagnoses/100 babies } \\
\text { (95\% } \mathbf{~ C l )}\end{array}$ \\
\hline No of diagnoses & $406(8.3)$ & $482(9.9)$ & $1.6(0.3$ to 2.7$)$ \\
\hline Musculoskeletal conditions: & & & \\
\hline Total No & $172(3.6)$ & $236(4.8)$ & $1.2(0.4$ to 1.9) \\
\hline Hip anomalies & $137(2.8)$ & $176(3.6)$ & - \\
\hline Musculoskeletal anomalies & $15(0.3)$ & $28(0.6)$ & - \\
\hline Other deformities of limb & $20(0.4)$ & $32(0.7)$ & - \\
\hline Cardiovascular disease & $59(1.2)$ & $55(1.1)$ & - \\
\hline Abdominal & $4(0.1)$ & 0 & $-0.1(-0.5$ to 0.3$)$ \\
\hline Facial & $46(1.0)$ & $53(1.1)$ & $-0.1(-0.6$ to 0.4$)$ \\
\hline Genitourinary & $75(1.5)$ & $79(1.6)$ & $-0.1(-0.6$ to 0.2$)$ \\
\hline Other & $50(1.0)$ & $59(1.2)$ &
\end{tabular}

${ }^{*}$ Data source: Scottish morbidity records 11 and $11(\mathrm{E})$.

Table 3 Routine assessments at 8 weeks and 8 months of age and contacts with general practitioners in first year in babies according to whether they underwent one or two neonatal screening examinations before discharge from hospital. Values are numbers (percentages ${ }^{\star}$ ) of babies

\begin{tabular}{|c|c|c|c|}
\hline Detail & $\begin{array}{c}\text { One screen } \\
\text { policy }(\mathrm{n}=4835)\end{array}$ & $\begin{array}{l}\text { Two screen policy } \\
(\mathrm{n}=4877)\end{array}$ & $\begin{array}{c}\text { Difference in } \\
\text { percentage }(95 \% \mathrm{Cl})\end{array}$ \\
\hline \multicolumn{4}{|l|}{ Assessment at 8 weekst: } \\
\hline No of babies & 4741 & 4781 & \\
\hline Abnormal & $498(10.5)$ & $506(10.6)$ & $-0.1(-1.3$ to 1.2$)$ \\
\hline Follow up in primary care & $299(6.3)$ & $272(5.7)$ & $0.6(-0.4$ to 1.6$)$ \\
\hline Referral to secondary care & $138(2.9)$ & $151(3.2)$ & $-0.2(-0.9$ to 0.4$)$ \\
\hline \multicolumn{4}{|l|}{ Assessment at 8 monthst: } \\
\hline No of babies & 4649 & 4590 & \\
\hline Abnormal & $984(21.2)$ & $973(21.2)$ & $<-0.1(-1.7$ to 1.6$)$ \\
\hline Follow up in primary care & $794(17.1)$ & $739(16.1)$ & $1.0(-0.5$ to 2.5$)$ \\
\hline Referral to secondary care & $174(3.7)$ & $199(4.3)$ & $-0.6(-1.4$ to 0.2$)$ \\
\hline Sample $(10 \%)$ of trial babies $\ddagger$ & 486 & 490 & - \\
\hline Respondents & $431(88.7)$ & $442(90.2)$ & - \\
\hline No of contacts with GP (No/100 babies) & $3738(867)$ & $3697(836)$ & - \\
\hline $\begin{array}{l}\text { Contacts resulting in secondary referral } \\
\text { (No/100 babies) }\end{array}$ & $100(23)$ & $110(25)$ & - \\
\hline
\end{tabular}

*Percentages calculated with exclusion of categories with missing information. †Data source: community health index records.

†Data source: general practitioner questionnaire for $10 \%$ subsample of babies.

\section{Discussion}

Most (90\%) babies born during the study period were included in the trial, representing all those for whom routine neonatal screening was appropriate. The lower than expected rate of diagnoses in the trial babies $(10 \%$ rather than $12 \%$ ) probably reflects the relatively higher risk among babies who were ineligible because they were admitted directly to the neonatal unit. 
Table 4 Outpatient and inpatient care in first year of life in babies according to whether they underwent one or two neonatal screening examinations before discharge from hospital after birth. Values are numbers (percentages) of babies

\begin{tabular}{|c|c|c|c|}
\hline Detail & $\begin{array}{l}\text { One screen policy } \\
\qquad(\mathrm{n}=4835)\end{array}$ & $\begin{array}{c}\text { Two screen } \\
\text { policy }(\mathrm{n}=4877)\end{array}$ & $\begin{array}{c}\text { Difference in } \\
\text { percentage }(95 \% \mathrm{Cl})\end{array}$ \\
\hline \multicolumn{4}{|l|}{ Outpatients* } \\
\hline Total No of referrals & 1091 & 1184 & - \\
\hline No with at least one outpatient referral & $896(18.5)$ & $973(19.9)$ & $-1.4(-2.9$ to 0.1$)$ \\
\hline \multicolumn{4}{|l|}{ Specialty: } \\
\hline Orthopaedic surgery & $289(6.0)$ & $340(7.0)$ & $-1.0(-1.9$ to -0.02$)$ \\
\hline Ophthalmology & $126(2.6)$ & $134(2.7)$ & - \\
\hline Medical paediatrics & $311(6.4)$ & $316(6.4)$ & - \\
\hline Other & $365(7.5)$ & $394(8.1)$ & - \\
\hline \multicolumn{4}{|l|}{ Inpatients $†$} \\
\hline Total No of admissions & 1034 & 1015 & - \\
\hline $\begin{array}{l}\text { No with at least one inpatient } \\
\text { admission }\end{array}$ & $753(15.6)$ & $718(14.7)$ & $0.9(-0.1$ to 2.2$)$ \\
\hline \multicolumn{4}{|l|}{ First inpatient admission only: } \\
\hline \multicolumn{4}{|l|}{ Type of admission: } \\
\hline Planned admission & $183(3.8)$ & $188(3.9)$ & - \\
\hline Emergency admission & $570(11.9)$ & $530(10.9)$ & - \\
\hline \multicolumn{4}{|l|}{ Specialty: } \\
\hline Orthopaedic surgery & $13(0.3)$ & $10(0.2)$ & - \\
\hline Ophthalmology & $15(0.3)$ & $13(0.3)$ & - \\
\hline Medical paediatrics & $462(9.6)$ & $428(8.8)$ & - \\
\hline Other & $263(5.4)$ & $267(5.5)$ & - \\
\hline
\end{tabular}

*Data source: Scottish morbidity record 0 .

†Data source: Scottish morbidity record 1

Table 5 Follow up of trial babies at orthopaedic and cardiac clinics according to whether they underwent one or two neonatal screening examinations before discharge from hospital after birth. Values are numbers (percentages) of babies

\begin{tabular}{|c|c|c|c|}
\hline Detail & $\begin{array}{c}\text { One screen } \\
\text { policy }(n=4835)\end{array}$ & $\begin{array}{l}\text { Two screen policy } \\
(\mathrm{n}=4877)\end{array}$ & $\begin{array}{c}\text { Difference in } \\
\text { percentage }(95 \% \mathrm{Cl})\end{array}$ \\
\hline \multicolumn{4}{|l|}{ Orthopaedic clinic* } \\
\hline \multicolumn{4}{|l|}{ Suspected hip problem at birth: } \\
\hline Total No & $137(2.8)$ & $176(3.6)$ & $-0.8(-1.5$ to -0.1$)$ \\
\hline No followed up at clinic & $125(2.6)$ & $167(3.4)$ & - \\
\hline No who required treatment & $15(0.3)$ & $12(0.2)$ & \\
\hline $\begin{array}{l}\text { No who had reduction under general } \\
\text { anaesthesia }\end{array}$ & $3(0.1)$ & $1(<0.1)$ & - \\
\hline \multicolumn{4}{|c|}{ Hip problems not suspected at birth but babies later referred: } \\
\hline Total No & $71(1.5)$ & $77(1.6)$ & $-0.1(-0.6$ to 0.4$)$ \\
\hline No who required treatment & $8(0.2)$ & $5(0.1)$ & - \\
\hline $\begin{array}{l}\text { No who had reduction under general } \\
\text { anaesthesia }\end{array}$ & $5(0.1)$ & $1(<0.1)$ & - \\
\hline \multicolumn{4}{|c|}{ Babies with no click at birth but referred because of family history of hip problem: } \\
\hline Total No & $46(1.0)$ & $35(0.7)$ & $0.2(-0.1$ to 0.6$)$ \\
\hline No who required treatment & $3(<0.1)$ & $1(<0.1)$ & - \\
\hline $\begin{array}{l}\text { No who had reduction under general } \\
\text { anaesthesia }\end{array}$ & 0 & 0 & - \\
\hline \multicolumn{4}{|l|}{ Cardiac clinic† } \\
\hline $\begin{array}{l}\text { No with suspected heart problem at } \\
\text { discharge from hospital after birth }\end{array}$ & $43(0.9)$ & $49(1.0)$ & $-0.1(-0.5$ to 0.3$)$ \\
\hline Confirmed at heart clinic & $29(0.6)$ & $35(0.7)$ & $-0.1(-0.4$ to 0.2$)$ \\
\hline $\begin{array}{l}\text { No not suspected at discharge but later } \\
\text { confirmed at heart clinic }\end{array}$ & $15(0.3)$ & $13(0.3)$ & $<0.1(-0.2$ to 0.3$)$ \\
\hline
\end{tabular}

*Data source: orthopaedic clinic database.

†Data source: cardiac clinic records.

\section{Methodological issues}

The trial was a pragmatic comparison of two policies as they might be used in hospitals. It was therefore expected that some of those allocated one examination would actually have a second and that some allocated two examinations would have only one. As we based the analyses on "intention to treat," however, we should have avoided the introduction of any bias. Possible bias introduced in assessing outcome was also minimised by using routinely collected data and blinding of providers of data to policy allocation.

We believe that the screening policies were similar to those implemented in other hospitals in the United Kingdom. Policies for type and grade of staff who carry out neonatal screening vary across the country. Our study reflects practice as carried out by experienced paediatricians or those in training rather than other specialties.

\section{Congenital diagnoses}

The trial has shown clearly that examining babies in hospital twice rather than once resulted in more congenital abnormalities being suspected at the time of discharge (see table 2). The excess may have resulted from more babies being examined by experienced staff, because a second examiner might detect something missed at first, or because of new conditions which developed over time. These extra "diagnoses," however, did not lead to any detectable increase in interventions that might improve infant health nor did the infants from one group make extra use of emergency services, as might have been expected if important conditions had been missed in hospital. Thus there was no evidence that one examination was less effective than two in identifying babies who required medical attention.

\section{Hip anomalies}

The larger number of congenital abnormalities diagnosed at birth in the group examined twice was primarily attributable to an excess in suspected hip anomalies. This resulted in extra referrals to outpatient departments $(2.6 \% v 3.4 \%$, see table 5$)$. These extra visits did not lead to more active management, and similar numbers underwent splinting or operation in both groups. A second examination did not therefore seem to improve sensitivity but did reduce specificity, which led to apparently unnecessary intensive surveillance.

Indeed, the higher false positive rate associated with the two examination policy may be more likely to result in extra, iatrogenic damage (for example, avascular necrosis of the femoral head) than to prevent long term disability. ${ }^{11}{ }^{12}$ If performance of neonatal screening only once did fail to detect significantly more genuine congenital displacement of the hip we would expect the "missed" babies to have appeared as extra referrals from the community. This was not the case, suggesting that the fluctuation in surgery rate was simply due to chance.

The poor detection rate for congenital displacement of the hip by neonatal screening corroborates a recent United Kingdom survey of hip screening (70\% who required surgery were missed by routine screening). The overall surgery rate, of about 1 per 1000 , was in keeping with the rate observed in that study. ${ }^{13}$

\section{Heart anomalies}

Most cases of serious cardiac anomaly first present with clinical symptoms ${ }^{14}$ and therefore the value of routine neonatal screening has been questioned. ${ }^{7}$ In this trial there was no clear evidence that a policy of more intensive screening led to a difference in the number of 
Key messages

- Neonatal screening in hospital after delivery can be safely carried out once rather than twice

- Introduction of this policy would save hospital resources, both during the postnatal period and subsequently through fewer outpatient consultations

- Later surveillance is an essential complement to hospital screening (whether performed once or twice) to detect abnormalities missed in hospital and conditions which develop after discharge

babies suspected of having serious cardiac problems at discharge.

\section{Community screening}

The trial confirmed the need for further surveillance after a baby leaves hospital. Of the 44 babies who received active management for congenital dislocation of the hip, $13(30 \%)$ had negative findings on the Ortolani-Barlow manoeuvre in hospital and were later detected in the community. Of the 10 babies who required surgery, six $(60 \%)$ were not detected in hospital.

In Scotland, later surveillance is provided by community screening at 8 weeks and 8 months, supplemented by opportunistic screening. As the numbers with later presenting problems were similar in the two groups there was no evidence that these cases were missed in hospital as a result of decreased neonatal screening but rather were identified as extra cases which were undetected equally in both groups. Therefore, any change in hospital policy must take into account the complementary nature of hospital and community screening.

\section{Conclusion}

Despite more suspected abnormalities among babies allocated a policy of two rather than one hospital neonatal examination the trial did not show any net health gain from this policy. A two screen policy does, however, carry additional resource implications for hospital services and extra anxiety for parents whose children are wrongly suspected of having abnormalities.

We thank the ward staff who made the study possible and the general practitioners who responded to the surveys. Ian Russell was an original grant holder and contributed to initial study design, Adrian Grant gave valuable comments on the analyses and draft reports, and James McLauchlan provided orthopaedic clinic data. The views expressed, however, are those of the authors.

Contributors: All authors were members of the Neonatal Examination and Screening Trial (NEST) Steering Group and contributed to study design and implementation, analysis and interpretation of results, and writing. In addition, CG designed and piloted the study and is the guarantor for the work. CR and MC carried out the statistical design and analysis, AM implemented daily administration and case note and data extraction, coding and entry, JAR carried out routine neonatal screening, PB provided extra cardiac clinic data, and DL provided extraction of data from case notes

Funding: The Health Services Research Unit is funded by the Chief Scientist Office of the Scottish Office Department of Health, which also funded the study through a project grant. Competing interests: None declared.

1 Maternity Services Advisory Committee to the Secretaries of State for Social Services and for Wales. Maternity care in action part III: care of the mother and baby (postnatal and neonatal care). London: HMSO, 1985.

Robinson R. Effective screening in child health. BMJ 1998;316:1-2.

3 Hall DMB. Health for all children. A programme for child health surveillance. Oxford: Oxford University Press, 1989.

4 Moss GD, Cartlidge PHT, Speidel BD, Chambers TL. Routine examination in the neonatal period. BMJ 1991;302:878-9.

5 Manning DJ. One or two neonatal examinations? BMJ 1991;302:1209. Hughes AP, Stoker AJ, Milligan
examinations? BMJ 1991;302:1209.

Cartlidge PHT. Routine discharge examination of babies: is it necessary? Arch Dis Child 1992;67:1421-2.

8 Cochran WG, Cox GM. Experimental designs. New York: Wiley, 1957.

9 Daly LE, Bourke GJ, McGilvray J. Interpretation and uses of medical statistics. Oxford: Blackwell Scientific Publication, 1991.

10 Barlow TG. Early diagnosis and treatment of congenital dislocation of the hip.J Bone Joint Surg 1962;44B:292-301.

11 Kalamchi A, MacEwen GD. Avascular necrosis following treatment of congenital dislocation of the hip. J Bone Joint Surg Am 1980;62:876-88.

12 Bradley J, Wetherill M, Benson MK. Splintage for congenital dislocation of the hip. Is it safe and reliable? J Bone Joint Surg Br 1987;69:257-63.

13 Godward S, Dezateux C. Surgery for congenital dislocation of the hip in the UK as a measure of outcome of screening. Lancet 1998;351:1149-52.

14 Abu-Harb M, Wyllie J, Hey E, Richmond S, Wren C. Presentation of obstructive left heart malformations in infancy. Arch Dis Child Fetal Neonatal Edition 1994;71:179-83.

(Accepted 9 November 1998)

\title{
Commentary: "Switchback" allocation-dangerous bends ahead!
}

\author{
Jonathan J Deeks
}

Switchback or reversal trials are an extension of the classic crossover trial design with participants "switching back" to their initial treatment in an additional period added at the end of the trial. ${ }^{1}$ Switchback designs have useful statistical properties when there are temporal trends in outcome that vary between subjects. They have been applied, for example, in cattle feeding and lactation experiments where the outcome (milk yield) is expected to decrease naturally throughout the trial. ${ }^{2}$ Occasionally they have been used in medicine for nutritional experiments. ${ }^{3}$

But Glazener and colleagues' rationales for using an extended switchback design relate more to ease of trial organisation than statistical efficiency. While the switchback design would control for ward specific tem- poral trends in rates of abnormality, it is difficult to conceive of a plausible mechanism by which such trends could arise. Given that it is the wards and not the neonates which switch (the neonates each receive only one intervention) it is perhaps unhelpful to think of this study as having a crossover form at all. In fact the data are analysed and presented as if they originate from a simple two group parallel study without any crossover or clustering features, by assuming that for each screening policy the underlying distribution of detected abnormalities is the same in every ward. ${ }^{4}$ As there is no reason to suspect non-random clustering of cases within wards and as just one team undertook the screening throughout the hospital this simplification is probably justified. 
There are attractive benefits of allocating screening policies to wards rather than individuals. As all participants allotted to each of the screening policies would always be located together trial execution will have been simplified, the risk of contamination reduced, and the bureaucracy of organising individual allocations avoided. The issues concerning consent to be randomised also differ in cluster randomised trials, which will have impacted on the ease of recruiting large numbers.

Simplifications of trial design, however, rarely come without jeopardising internal validity. To ensure proper random allocation the allocation mechanism must be truly random and the allocations concealed at the time they are assigned. ${ }^{5}$ The random element aims to prevent the misfortune of allocation patterns coinciding with, or being influenced by, a factor related to the outcome. Concealment of the allocation prevents the possibility of conscious or subconscious manipulation of individual assignments. There is empirical evidence that unconcealed randomisation leads to overestimation of treatment effects, ${ }^{6}$ manipulation possibly occurring by participants' registrations being delayed until they would receive the preferred treatment allocation or exclusion of eligible subjects whose allotted allocation would be considered unfavourable.

In this trial, despite the use of a random mechanism to assign the intervention switching policies to the wards, the allocation of a mother to a ward was by the standard haphazard (not really random) process of hospital bed allocation. While such a mechanism may seem difficult to influence it certainly is not concealed. As these criteria are not met the authors cannot guarantee that they have allocated the participants to the two groups in an unbiased manner. For the allocation to have been seriously biased, however, it would be necessary for assignments to have been made with some knowledge of each individual's likely outcome, so that the allocation of some mothers carrying babies of higher (or lower) risk could be manipulated in favour of a particular policy. While such manipulation is a reality in poorly randomised treatment trials, there may be situations in trials of preventive and screening interventions when no risk factors can be identified at the time of assignment to intervention and biased allocation is theoretically impossible. The interpretation of this trial relies on just such an assumption.

1. Jones B, Kenward MG. Design and analysis of cross-over trials. London: Chapman and Hall, 1989:203-4.

Cochran WG, Cox GM. Experimental designs. 2nd ed. New York: Wiley, 1957:141-2.

3 Meng QH, Pajukanta P, Valsta L, Aro A, Pietinen P, Tikkanen MJ. Influence of apolipoprotein A-1 promotor polymorphism on lipid levels and responses to dietary change in Finnish adults. I Intern Med 1997:241:373-8.

4 Campbell MK, Grimshaw JM. Cluster randomised trials: time for improvement. BMJ 1998;317:1171-2.

5 Schulz KF. Randomised trials, human nature, and reporting guidelines. Lancet 1996;348:596-8.

6 Schulz KF, Chalmers I, Hayes RJ, Altman DG. Empirical evidence of bias. Dimensions of quality associated with estimates of treatment effects in controlled trials. JAMA 1995;273:408-12.

\section{A patient who changed my practice Footsteps and faces}

It is said that a bird's eye view changes the perspective even of familiar things, but it was a bed's eye view that changed mine. Completely bed bound, unable to use a commode, I had a peculiar perspective on people passing through the ward. Their comings and goings became a series of footsteps and faces and, if I was lucky, smiles and voices.

I heard footsteps, quick yet purposeful, and a figure came into view. The face looked towards the floor, avoiding eye contact, but I could make out a frown across his forehead. Bustling along, appearing hassled and giving out signals which say, "I'm busy, don't bother me." It's a junior doctor, wearing a white coat with pockets bulging. I don't recognise him. "He's not part of my team," I thought, "but I've seen so many, I'm not even sure who my team is anyway."

More footsteps, sophisticated this time. High heels clicking on the floor, strutting rather than walking. As she comes into view she's not in uniform, no white coat, but an identification badge hangs off her lapel. Her head held high with an air of importance or is it arrogance? Must be a manager of sorts. But I wouldn't know; I've only ever met two. Another walks along, slowly, occasionally pausing. I wait, wondering, will they ever reach my viewing zone? They'd better because I'm intrigued; who are they, why are they walking so slowly? Next, eyes look me up and down, and up and down again just to get a good look, and it's written all over his face.

"What's wrong with her, poor thing, she's so young?"

He avoids my gaze, almost embarrassed but not enough to stop him lingering before moving on.

Who's this now? Purposeful footsteps again but not rushed and definitely not strutting, busy but not overburdened. The footsteps come into view and a face looks at me. Has she got the wrong person? I don't recognise the nurse wearing an agency uniform. But she looks, meets my gaze, and then smiles. A kind smile, one that acknowledges me and in a split second says, "Hi ... and bye," it says, "I see you lying in bed and I see you as a person with feelings.” Suddenly she's gone, but I am left with a warm feeling and my spirits lifted.

Shuffling this time, is it a child dragging his or her feet or an old man in slippers unable to pick his feet up? No, it's too quick for that; who is it? Any second now they'll be visible-oh yes, an anaesthetist. I smile to myself, knowing that I too drag my theatre shoes, but my thoughts are interrupted as the anaesthetist raises his eyebrows and mutters, "Hiya. All right?" "Yes thanks," I reply.

We exchange a nodding of heads and he continues on his way. The interchange took less than 30 seconds yet he was the first person today to speak to me of his own accord. Granted he had to talk to me a few days ago during the preoperative visit but not today; he had other patients to see.

I reflected; you can look at walls and floors with no reaction, but you can't look at someone without evoking a response because people generate thoughts and feelings. From that moment I resolved never again to hide behind my footsteps and face but to reach out to patients and reveal my smile, my voice.

It makes a difference; I know, I was that patient.

Michelle White, anaesthesia senior house officer, Bristol

We welcome articles of up to 600 words on topics such as A memorable patient, A paper that changed my practice, My most unfortunate mistake, or any other piece conveying instruction, pathos, or humour. If possible the article should be supplied on a disk. Permission is needed from the patient or a relative if an identifiable patient is referred to. We also welcome contributions for "Endpieces," consisting of quotations of up to 80 words (but most are considerably shorter) from any source, ancient or modern, which have appealed to the reader. 